Research Article

\title{
Experimental Study on the Complex Contact Frictional Property of an Ultralong Distance Large-Section Concrete Pipe Jacking and Prediction of Pipe String Stuck
}

\author{
Ziyong $\mathrm{He}^{1,2}$ and Jiangong Chen $\mathbb{i}^{1,2}$ \\ ${ }^{1}$ School of Civil Engineering, Chongqing University, Chongqing 400045, China \\ ${ }^{2}$ National Joint Engineering Research Center for Prevention and Control of Environmental Geological Hazards in The TGR Area, \\ Chongqing University, Chongqing 400045, China
}

Correspondence should be addressed to Jiangong Chen; cjg77928@126.com

Received 25 November 2018; Revised 11 April 2019; Accepted 18 April 2019; Published 29 May 2019

Academic Editor: Antonio Caggiano

Copyright (c) 2019 Ziyong He and Jiangong Chen. This is an open access article distributed under the Creative Commons Attribution License, which permits unrestricted use, distribution, and reproduction in any medium, provided the original work is properly cited.

\begin{abstract}
Line 2 of the Guanjingkou Pipe Jacking Project in Chongqing encountered a pipe sticking problem, whose occurrence was inevitably attributed to the higher total frictional resistance of pipe strings rather than the maximum jacking force. Line 1 , which is about to start construction, has basically the same construction environment as Line 2 using the same microshield and pipe string sizes. To avoid repeating the pipe sticking problem of Line 2 , the mutual friction characteristics between the surrounding rocks and jacked pipe strings are studied for Line 1 by adopting the same test method under seven complex contact conditions (the presence or various combinations of three substances, i.e., extrapipe string field debris, bentonite slurry, and sand-laden waste slurry, on the jacked pipe string-surrounding rock contact surface are mainly considered). The results show that sufficient bentonite slurry can effectively reduce the frictional resistance, and when the amount of bentonite is insufficient, the average friction coefficient (AFC) of the later contact surface increases by $50 \% \sim 70 \%$. The comparison of the monitored versus predicted jacking forces indicates that the value predicted by the test is slightly higher than the monitored force and the variation trends of the two match well, thus proving the correctness of the test results. It is possible to continue predicting the variation trends of the jacking force and frictional resistance based on the contact situation outside the pipe string wall, which greatly lowers the probability of re-encountering pipe sticking. The test results not only explain the important role of bentonite slurry in reducing the pipe string wall frictional resistance but also suggest that an increase in the pipe string wall frictional resistance resulting from the complex contact inflow into the overexcavation gap is the root cause of pipe sticking; moreover, the number of jacked pipe strings matching a single IJS is the second cause of pipe string sticking. The methodology of this study can provide a reference for other studies concerning the jacking force of long-distance rock microshield tunnelling.
\end{abstract}

\section{Introduction}

Large-section pipe jacking has begun to emerge with the application of pipe jacking technique in the energy transportation projects, the municipal infrastructure construction, and the water conservancy and hydropower engineering. Nevertheless, it may encounter many engineering problems, one of which is the pipe string stuck.

With the continuous development of the technology, the pipe jacking method has occupied a position in infrastructure construction $[1,2]$. In recent years, the research focus of pipe jacking has been the interaction between pipe string and surrounding complex soil environments [3-5], the indoor experiments [6-10], the numerical simulation [11-13], and the field investigation [14].

Since pipe sticking is fundamentally caused by a higher total frictional resistance on pipe strings rather than jacking force, relevant research still needs to be carried out regarding the relationship between the jacking force and the frictional resistance during pipe jacking. Given few studies on the 
large-section long-distance microshield concrete pipe string jacking at present, we have studied the pipe-surrounding rock interactive friction characteristics with a large-scale rock direct shear system under complex contact conditions [15-17] based on the actual site situation by methods provided in reference [7] (Yen and Shou, 2015). Furthermore, the matching relationship between the in situ jacking force and the pipe string frictional resistance was investigated based on a combination of the test outcomes with the empirical formula, the maximum number of pipe strings driven by the IJSs was predicted, and the pipe sticking problem in Line 2 was solved successfully. Line 1, which is about to start construction, is likely to encounter the same construction problems as Line 2 , and it has a similar construction environment and same microshield and pipe strings with the same size and specifications to Line 2 . Therefore, by adopting the previous methodology, this study explores the pipe-surrounding rock friction characteristics and predicts the maximum number of pipe strings driven by the IJSs under the complex contact conditions that may occur in Line 1 through an indoor test combined with an empirical formula. The test results show that the increase in the pipe string wall frictional resistance resulting from the complex contact inflow into the overexcavation gap is the root cause of pipe sticking, and the number of jacked pipe strings matching a single IJS is the second cause of pipe string sticking. The methodology of this study can provide a reference for other studies concerning the jacking force of long-distance rock microshield tunnelling.

\section{Project Overview}

2.1. Engineering Geological Condition. Nonpressure tunnel No. 2 has a mileage of $3+388 \sim 3+574$, and a tunnel depth of $14 \sim 212 \mathrm{~m}$. The surrounding rocks in this section are composed of the karst breccia, argillaceous dolomite, shale, and karst fills of the Triassic Leikoupo Formation. The strata dip steeply by $50^{\circ} \sim 60^{\circ}$. The karst development and rock mass integrity are poor for this section. The stratum crossed by Line 1 just under construction is precisely the dolomite of the Leikoupo Formation reservoir, whose main attitude elements and mechanical strength parameters are consistent with Line 2 . The longitudinal engineering geological profile of pipe tunnel No. 2 is shown in Figure 1. The corresponding mechanical strength parameters of the rock masses are listed in Table 1.

2.2. Project Overview. The mini shield used here has a maximum excavation diameter of $3220 \mathrm{~mm}$, whereas the matching pipe string has an outer diameter of $3170 \mathrm{~mm}$, an inner diameter of $2650 \mathrm{~mm}$, and a wall thickness of $260 \mathrm{~mm}$, as shown in Figures 2(a) and 2(b) [18]. A single pipe section is $2500 \mathrm{~mm}$ in length, which is prefabricated at the precast yard and is made of C50-reinforced concrete. Each pipe section was longitudinally arranged with two layers of main reinforcements, with each layer consisting of 60 HRB335 hot-rolled ribbed steel bars $12 \mathrm{~mm}$ in diameter, which were laid out symmetrically at a spacing of $150 \mathrm{~mm}$ [18].
Circumferential reinforcements were the same in specifications as the longitudinal reinforcements, with a spacing of $100 \mathrm{~mm}$, as shown in Figure 2(c).

Aside from the design and installation of IJSs, the drag reduction measures for long-distance pipe jacking also include the pipe string exterior grouting, which reduces the frictional resistance between the pipe string walls and the surrounding rocks. The lubricating slurry used in the project is composed of bentonite, sodium carboxymethyl cellulose (CMC), soda ash, polyacrylamide, and high polymer material. The grouting holes on the pipe strings are distributed symmetrically on the pipe sections at equal angles of $120^{\circ}$. Meanwhile, the pipe strings with grouting holes are laid out in the longitudinal direction, each at an interval of five pipe strings $(12.5 \mathrm{~m})$, as shown in Figure 3. For Line 1, use of the same lubricating material as the line 2 is intended, as well as the same layout of pipe strings with grouting holes [19].

2.3. Engineering Problems. A pipe sticking problem was encountered shortly after the pipe jacking entered the quartz sandstone formations. That is, the pipe strings could no longer continue movement by the jacking force of IJSs. The initial field investigation concluded that the microshield device used itself had no ability to effectively prevent the backward flow of gravel and that the grouting holes on the shield were closed due to manufacturing reasons and unusable. As a result, the microshield area was unable to effectively reduce the backward flow of gravel. Excessive accumulation of gravel outside the pipe string wall increased the surface friction resistance of pipe strings to result in pipe sticking.

As shown in Figure 4, it was found during the deslagging of pipe strings that the contact substances outside the pipe string wall consisted mainly of three types: (1) coarsegrained stones, with grain size ranging between 50 300 mm, as shown in Figure 4(b); (2) gravel slag, and (3) viscous substances, whereas the viscous component was mainly bentonite, as shown in Figure 4(d).

\section{Study of Pipe String Frictional Resistance}

3.1. Theoretical Research and Indoor Test. Because pipe sticking occurs when the total frictional resistance of pipe strings is higher than the jacking force, it is necessary to investigate the matching relationship between the frictional resistance and the jacking force during large-section concrete pipe jacking in complex geological conditions, that is, to further explore the optimization of the number of pipe strings between adjacent IJSs in complex geological conditions. The pipe string frictional resistance under complex contact conditions is studied using the empirical formula for estimating the frictional resistance in concrete pipe jacking described by Yen and Shou (2015):

$$
\mathrm{JF}_{\text {frict }}=\mu_{\text {int }} \frac{\gamma \cdot r \cdot \cos \left(45^{\circ}+\phi_{\mathrm{r}} / 2\right)}{\tan \phi_{\mathrm{r}}} \cdot \pi \cdot D \cdot L,
$$

where $\mathrm{JF}_{\text {frict }}$ is the frictional component of the jacking force, $\mu_{\text {int }}$ is the rock-pipe residual interface frictional coefficient, 


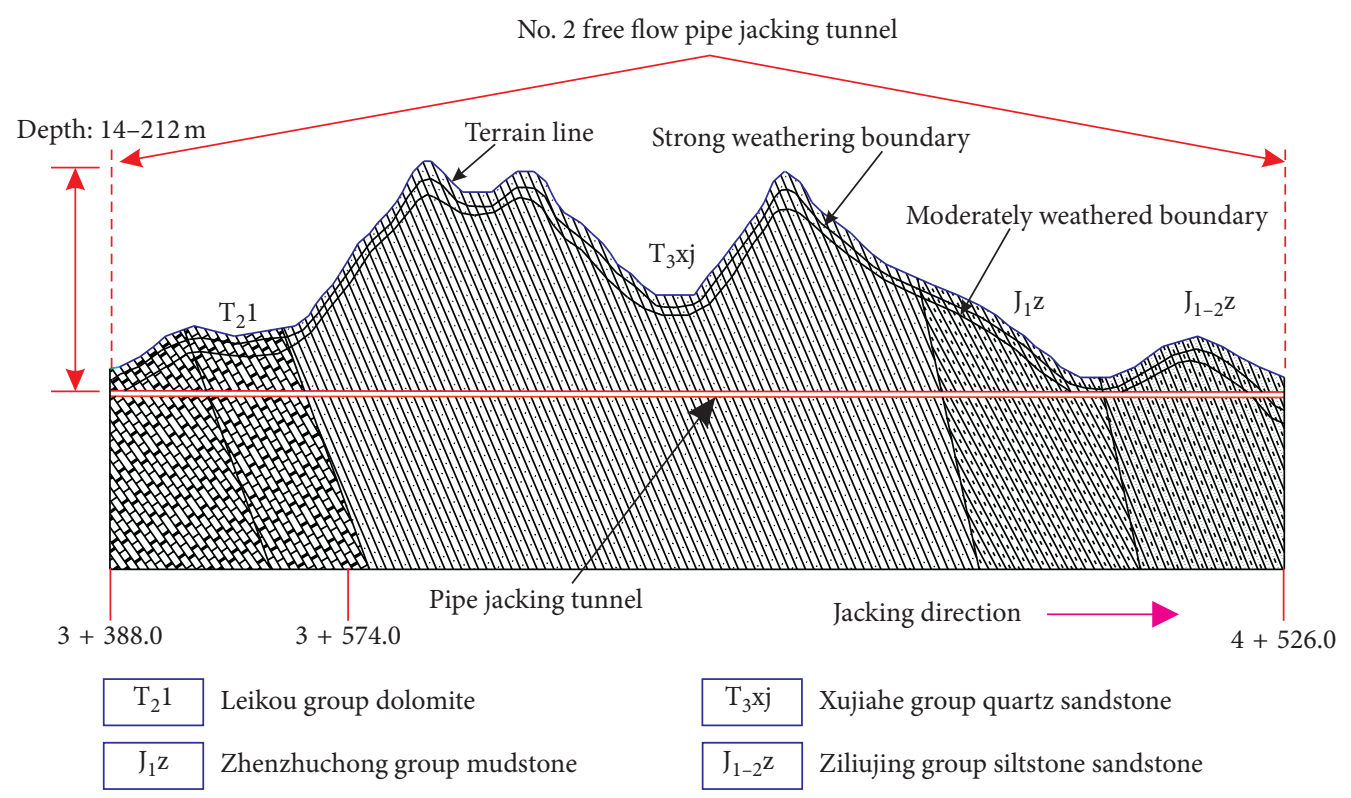

FIgUre 1: Plan view and geological section of the No. 2 pipe jacking tunnel.

TABLE 1: Comprehensive rock mass properties of the Guanjingkou pipe jacking project.

\begin{tabular}{lccccc}
\hline Stratum & $\mathrm{E}(\mathrm{GPa})$ & $\rho\left(\mathrm{kg} \cdot \mathrm{m}^{-3}\right)$ & $\mu$ & $\Phi\left({ }^{\circ}\right)$ & $c(\mathrm{kPa})$ \\
\hline Dolomite & 1.2 & 2500 & 0.30 & 31.3 & 0.60 \\
Quartz sandstone & 2.0 & 2500 & 0.32 & 31.0 & 0.40 \\
Mudstone & 1.7 & 2550 & 0.36 & 24.7 & 0.25 \\
Siltstone and & 2.0 & 2550 & 0.33 & 23.5 & 0.27 \\
sandstone & & & & &
\end{tabular}

$\gamma$ is the unit weight of rock, $\varphi_{\mathrm{r}}$ is the residual friction angle of rock, $D$ is the outer diameter of pipe string, $r$ is the pipe string radius, and $L$ is the length of pipe string.

It can be seen from (1) that $\mu_{\text {int }}$ is one of the critical factors in determining $\mathrm{JF}_{\text {frict }}$, a parameter that must be determined experimentally in complex contact conditions.

\subsection{Setup and Procedure of Shear Friction Tests}

3.2.1. Specimen Preparation and Testing Instrument. The rationale of the test is shown in Figure 5. The rock and concrete specimens produced certain displacements along the tangential direction of contact surface under normal force. The contact friction laws of the two were obtained by measuring the AFC at the contact surface.

As shown in Figure 5, the rock block was cut into a hexahedron of $130 \mathrm{~mm} \times 50 \mathrm{~mm} \times 50 \mathrm{~mm}$ (length $\times$ width $\times$ height), while the concrete base was $200 \mathrm{~mm} \times 85 \mathrm{~mm}$ $\times 50 \mathrm{~mm}$ (length $\times$ width $\times$ height) in size, with a $150 \mathrm{~mm} \times$ $60 \mathrm{~mm} \times 10 \mathrm{~mm}$ (length $\times$ width $\times$ height) rectangular groove at the top. All the materials used in the test were taken from the project site, and the mixing proportion of concrete was also set in strict accordance with the actual situation.

The frictional characteristics of the contact surface are associated with initial roughness of the contact surface; ensuring the validity of the test results, the surrounding rock surfaces in contact with pipe strings should be utilized as much as possible without disturbance when cutting the field surrounding rock samples. The concrete specimens should be inspected and screened using a roughness tester. The surface roughness $(\mathrm{Ra})$ of the concrete test specimens was $20.68 \mu \mathrm{m}$, while the average roughness of the jacking pipe string samples was $18.7 \mu \mathrm{m}$. The surfaces were considered sufficiently similar as to make worthwhile comparisons.

In this study, the indoor friction shear tests were completed with a rock shear rheometer, and Figure 6 shows the testing equipment. The specifications and technical parameters of the testing equipment are listed in Table 2.

3.2.2. Main Parameters of Lubricants. The main components of the slurry used in engineering include bentonite, CMC, soda, potable water, and high-molecular polymers. Table 3 shows their mixing proportions. The slurry viscosity was measured with a Marsh funnel. Specifically, the time taken for $946 \mathrm{ml}$ (1 quart) of slurry to leak from the Marsh funnel in the measuring cylinder is taken as the evaluation criterion. The average slurry viscosity measured using the Marsh funnel was $119 \mathrm{~s}$ in this study.

3.3. Direct Shear Friction Test Conditions. Long-distance rock-pipe jacking needs to overcome the friction resistance on the pipe string wall when it advances in the rock mass, while the friction resistance is closely related to the state of contact surface aside from the association with the normal force imposed on the pipe strings. According to the in situ pipe-rock contact situation, a series of pipe-rock shear friction tests under following seven types for contact conditions a-g were proposed. It is noteworthy that two types of contact conditions, i.e., conditions a and b, were virtually 


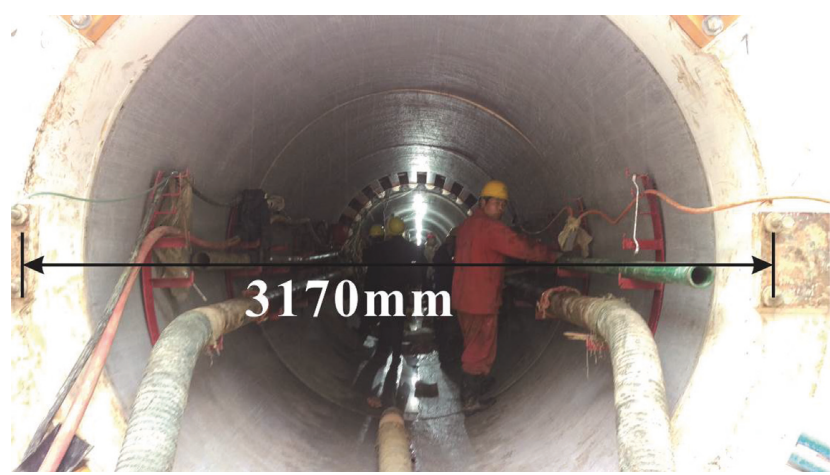

(a)

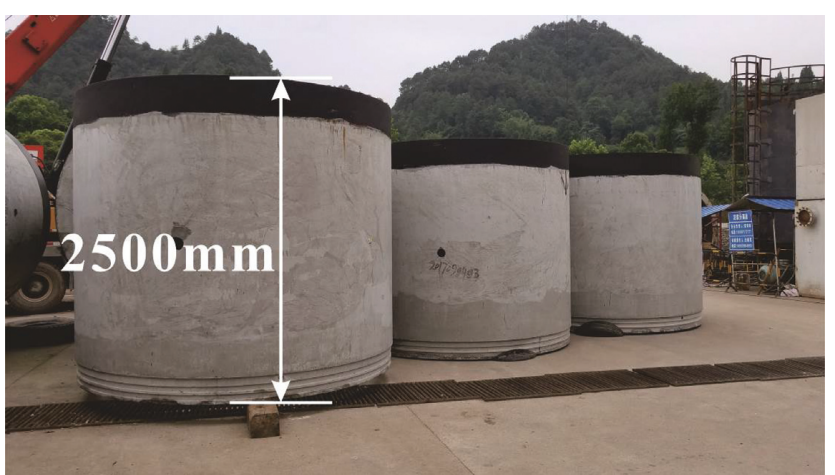

(b)

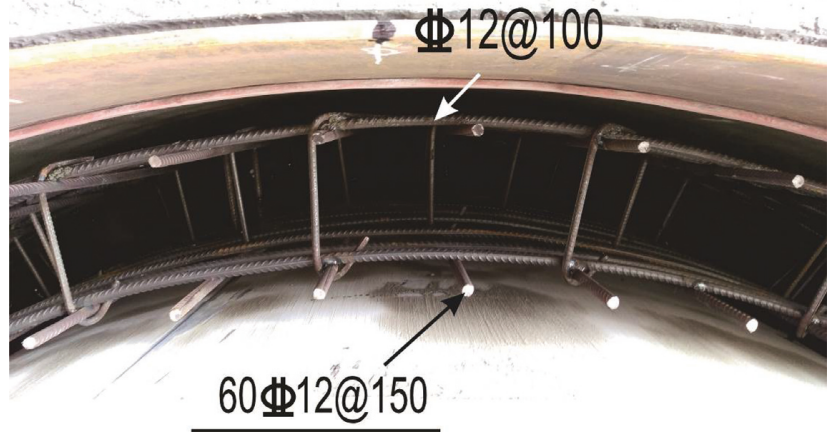

(c)

Figure 2: Structural diagram of pipe strings.

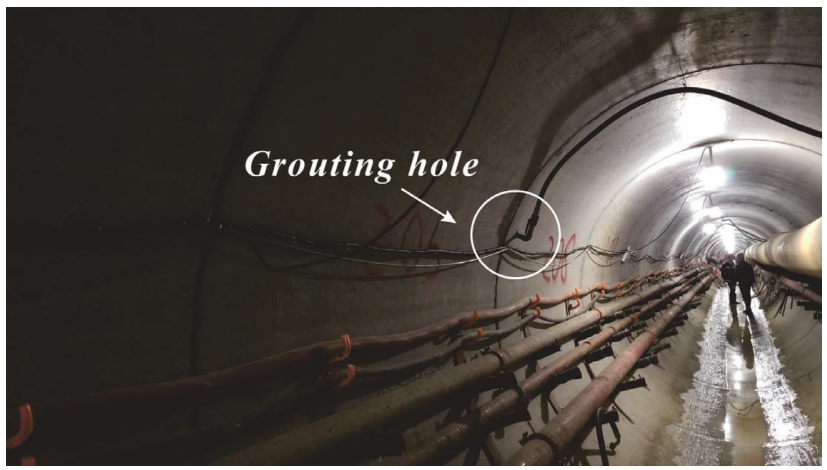

FIgURE 3: Spatial distribution of pipes with grouting holes.

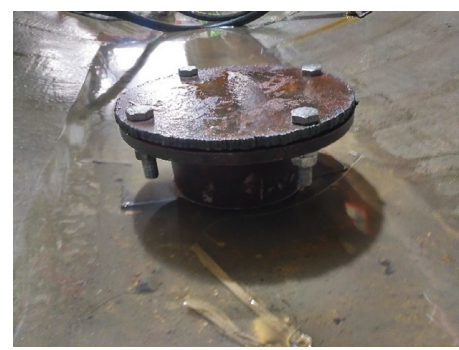

(a)

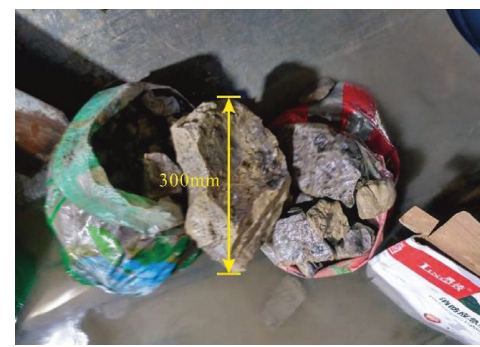

(b)

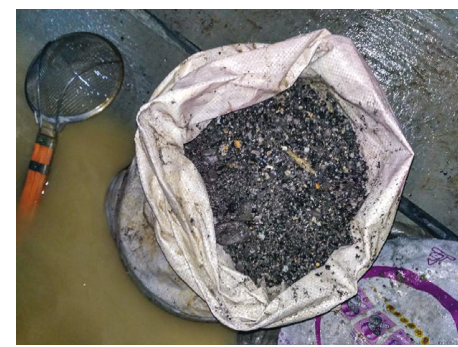

(c)

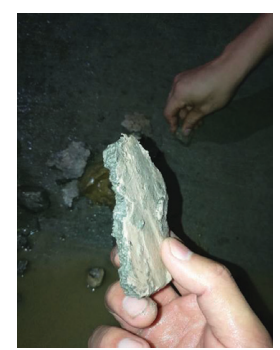

(d)

FIgURe 4: Perforating and deslagging of pipe string. (a) Deslagging hole. (b) Crushed ballast. (c) Coarse-grained stone. (d) Sticky material. 


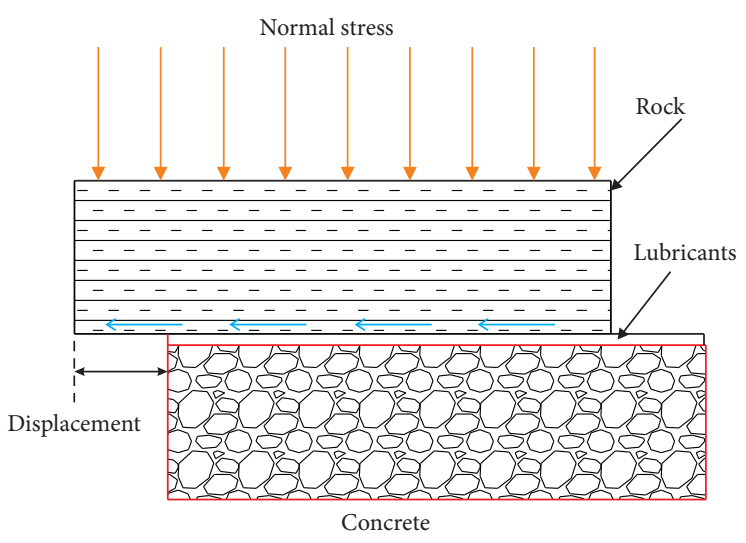

(a)

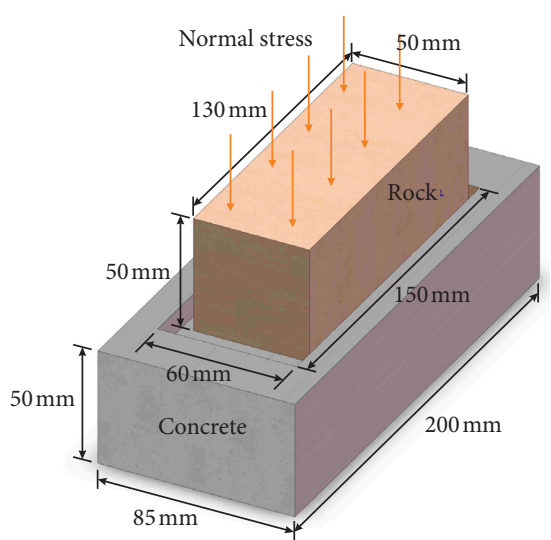

(b)

FIGURE 5: Interface friction testing in direct shear.

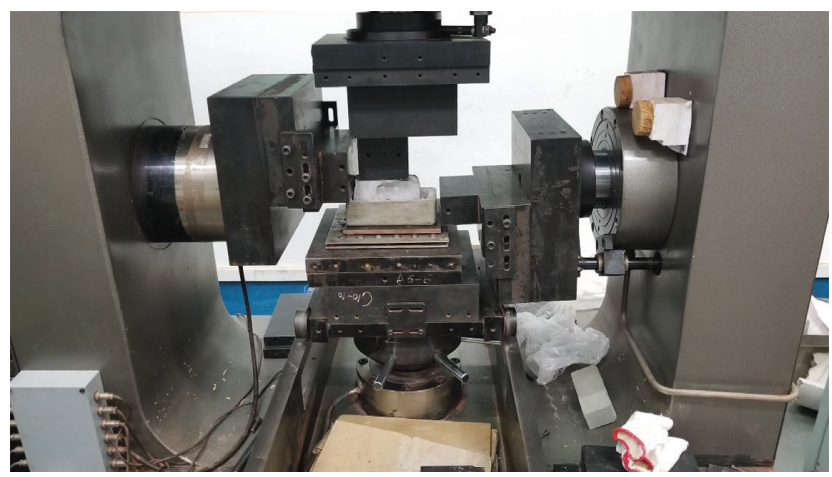

Figure 6: Rock shear rheometer.

TABle 2: Specifications and technical parameters of the rock shear rheometer.

Model

Direction of force

Maximum test force $(\mathrm{kN})$

Relative error of indication (\%)

Effective measurement range

Test force control stability

Test force resolution (1/code)

Minimum resolution (N)

$$
\text { Stroke }(\mathrm{mm})
$$

Displacement

Measurement and control range $(\mathrm{mm})$

Indication error

Displacement resolution

Maximum measuring range $(\mathrm{mm})$

Measurement range (\%FS)

Deformation

Control

parameters
Relative error of indication (\%FS)

Deformation resolution

$$
\text { Control mode }
$$

Axial, tangential loading rate $(\mathrm{mm} / \mathrm{min})$

Axial, tangential deformation rate $(\mathrm{mm} / \mathrm{min})$ Continuous operating time
The rock shear rheometer Axial (vertical)

600
Tangential (horizontal)

Better than \pm 0.5

$$
1-100
$$

$\leq \pm 1 \%$ indication

$1 / 300000$ (1 resolution over full range)

10

10

$$
\begin{gathered}
100 \\
0 \sim 100 \\
\pm 0.5 \\
0.001 \mathrm{~mm} \\
30 \\
0.4 \sim 100 \\
\pm 0.5 \\
0.001 \mathrm{~mm}
\end{gathered}
$$

Test force, displacement, deformation

$$
\begin{gathered}
0.1 \sim 100 \\
0.001 \sim 10
\end{gathered}
$$

Greater than 1,000 hours absent in the actual context, which though could be used for contrast purpose with other test results:

(a) Dry friction test with no contact medium at the contact surface (b) Dry friction test with presence of rock debris only at the contact surface

(c) Friction test where only the bentonite slurry is considered at the contact surface 
TABle 3: Components' ratio of thixotropic slurry.

\begin{tabular}{lccccc}
\hline \multirow{2}{*}{ Slurry type } & \multicolumn{5}{c}{ Ratio of components } \\
& Bentonite & CMC & Water & Soda & Polymer \\
\hline Compound slurry & 1 & 0.011 & 5.556 & 0.045 & 0.05 \\
\hline
\end{tabular}

(d) Friction test where a mixture of bentonite slurry and debris is acting on the contact surface

(e) Friction test with presence of waste slurry only at the contact surface

(f) Friction test with presence of a mixture of waste and bentonite slurries at the contact surface

(g) Friction test with presence of a mixture of waste slurry, rock debris, and bentonite slurry at the contact surface

In view of the rather complicated composition of extrapipe contact substances, the debris contact substances are classified by particle size, and the viscous contact substances are investigated by considering the compositional mass ratio, as shown in Figure 7. The debris removed from the exterior of multiple pipe strings on-site is subjected to particle size classification. As shown in Figure 7(a), debris of particle size below $1 \mathrm{~cm}$ represents $68 \%$ of the total amount of debris, of which debris of a particle size below $0.5 \mathrm{~cm}$ accounts for $43 \%$ of the total amount; thus, debris of a particle size less than $0.5 \mathrm{~cm}$ is taken as the research object of this test. Next, as shown in Figure 7(b), compositional analysis is performed on ten viscous samples after the in situ pipe string opening. For ease of comparison, the mass ratio of debris is normalized as 1 . According to the figure, the proportion of fine sands in the waste slurry varies between 3.5 and 4.3 , and the mass ratio of viscous substances is in the range from 2.7 to 3.5 . Thus, the mixing weight ratio of the three materials is set as $1: 3.9: 3.1$ in the test.

Since the contact state of contact substances on the contact surface was constantly changing during the tests, the friction coefficient method [7] was employed to facilitate the evaluation of test results under seven types of test conditions, as shown in formula (1):

$$
\tau=\sigma \mu,
$$

where $\tau$ is the shear force, $\sigma$ is the normal force, and $\mu$ is the contact surface friction coefficient.

\subsection{Test Steps and Precautions}

(1) The sandstone collected from the site was cut into hexahedrons with more precise dimensions. The rock masses should not be apparently ruptured or damaged during the processing. The processed sandstone specimens were sealed with a preservative film and then placed in a cool, dry place.

(2) The concrete specimens were used as the base plate of the tests, whereas the rock specimens were used as the upper plate. During the tests, the base plate moved driven by the hydraulic press, while the upper plate remained stationary, as shown in Figure 6. To avoid damage resulting from contact between various parts of the instrument, a rigid block was placed on the rock specimens to transfer the normal load. The bottom area of the steel block was nearly equal to the upper surface area of rock specimens, in order to achieve uniform transfer of the normal load. It should be noted that a ball bearing disk was placed under the concrete base to ensure that the shear force measured by the instrument basically came from the rock-concrete contact surface.

(3) During the tests, normal load was applied slowly first, and then the horizontal tangential load was initiated after stabilization of the normal load value within the set range. Three different normal dead loads $(4 \mathrm{kN}, 6 \mathrm{kN}$, and $8 \mathrm{kN})$ were applied to the upper part of the rock mass. A trial test was carried out for each test condition before the commencement of tests. Since the contact state of the contact surface between rock and concrete specimens changed all the time, the purpose of the trial tests was to determine whether there were certain similar laws in the shear curves of contact surface, so as to generalize the laws while adequately reducing the number of tests.

(4) The horizontal shear controller was initiated, and the shear displacement was controlled by the displacement control method during the tests. The displacement rate was set to $10 \mathrm{~mm} / \mathrm{min}$. The present tests included a total of 7 contact conditions and 3 normal pressures, which were equivalent to 21 test conditions. To simulate the pipe-rock contact state of the site, the contact media needed in the tests had all been retrieved from the site.

\section{Test Results}

As shown in Figure 8, 4(a)(I) indicates that the normal constant pressure applied in the test is $4 \mathrm{kN}$, the contact condition between concrete and sandstone is condition a, while (I) represents the type I test rule. Since the contact state between concrete and sandstone was complex, and the surface roughness of specimens varied, there were certain differences in the test results. Hence, the variation range of the friction coefficient was taken as the criteria for classifying test result curves. It is noteworthy that the contact substance in each test was added prior to the test only, without addition during the test.

As shown in Figure 8, in the initial stage of the test (the test frequency is 1 15), since the contact state between concrete and dolomite was complex, and the surface roughness of specimens varied, the corresponding AFC varied from 0.550 to 0.562 . When the contact surface was flattened continuously with the increase in the number of tests, the variation range of $\mathrm{AFC}$ of (II) series curves narrowed from $0.550-0.562$ to $0.521-0.529$, and the corresponding test frequency is between $38 \sim 50$.

It can be seen from (I) series curves in Figure 9 that the friction coefficient of contact surface was all along increasing 


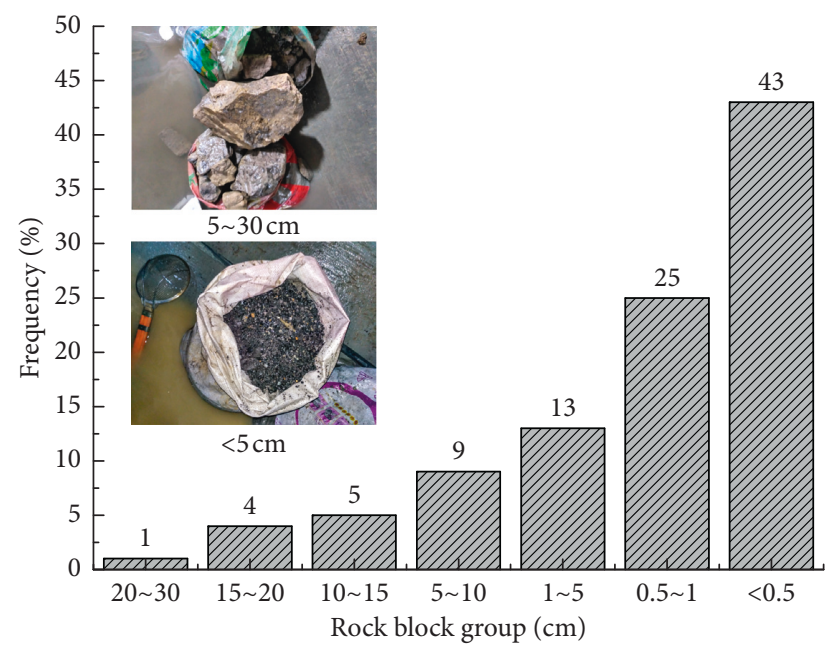

(a)

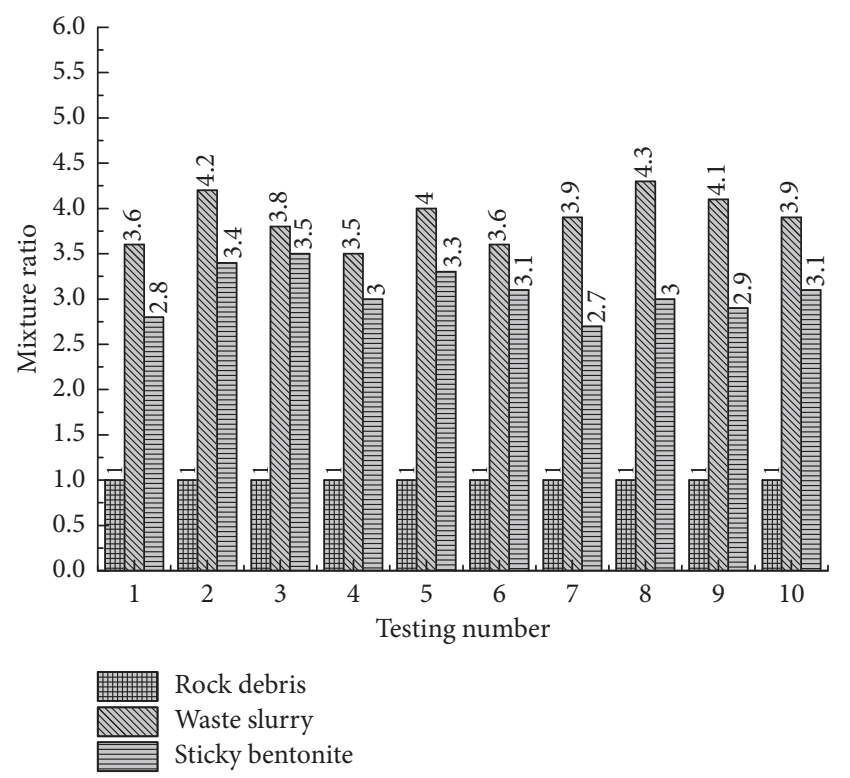

(b)

FIGURE 7: Rock block frequency distribution and sticky mixture ratio of the study area.

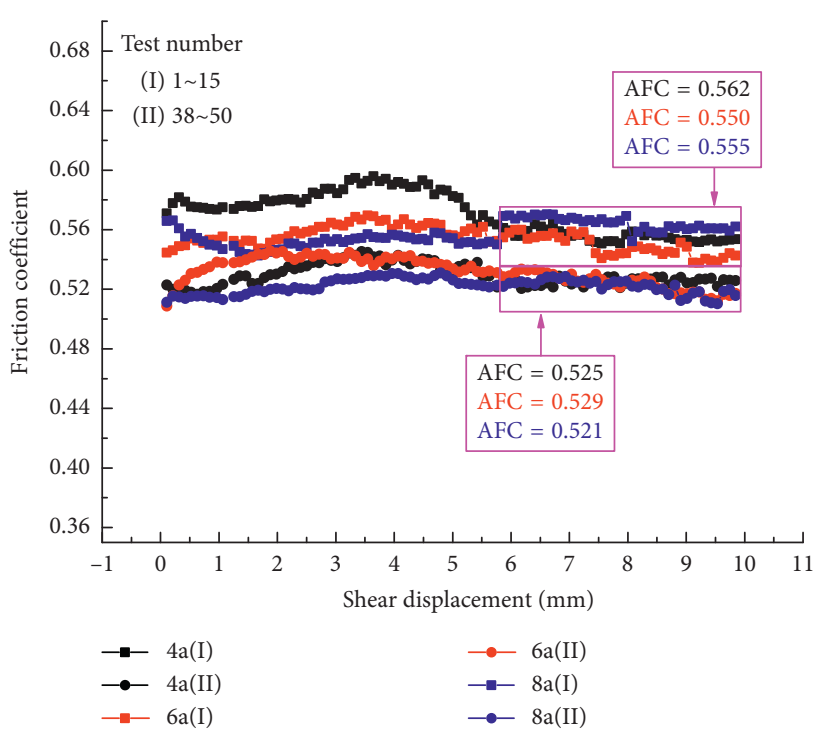

FIgURE 8: Direct shear testing results for dry friction tests.

at faster rates at the initial test stage, the normal force acted firstly on the larger grain size debris through the rock specimen, and sudden crushing occurred during the shear turbulence to result in a significant drop in the curve. The corresponding AFC varied from 0.573 to 0.582 . In addition, the breakage of debris was remarkably severer after more than 33 trials, no drop zone encountered in the (II) series curves with production of rock flour, while its fluctuation range was $0.517-0.543$. The variation ranges of the three were rather close, all of which were markedly lower than the (I) series curves, suggesting that the crushed debris was conducive to reducing the friction coefficient at the contact surface.

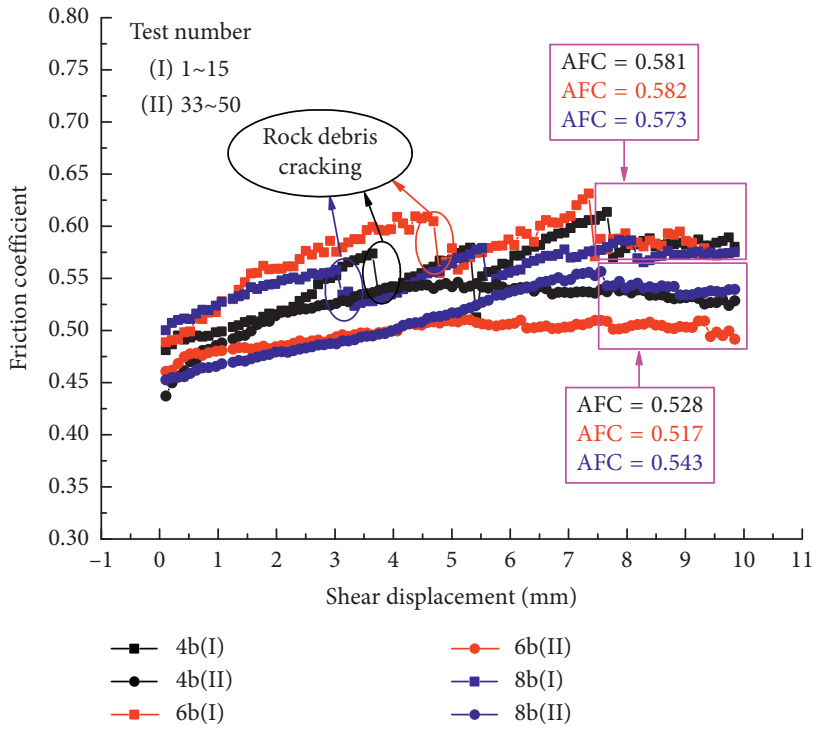

FIGURE 9: Direct shear testing results for the debris dry friction test.

Prior to the commencement of the test, a layer of bentonite lubricating slurry was filled in the base groove first to ensure that the contact surface was covered completely with the slurry. As can be seen from Figure 10, the AFC for the (I) series curves varies from 0.333 to 0.351 . On comparison with the previous two test conditions, it has been found that the bentonite slurry had a prominent drag reducing effect. An increase in the number of tests would lead to a continuous decrease in the slurry volume on the contact surface, while repeated friction would also increase the slurry consistency to strengthen the viscous resistance at the contact surface. Accordingly, the variation range of AFC increased to $0.453-0.471$ in the (II) series curves when the 


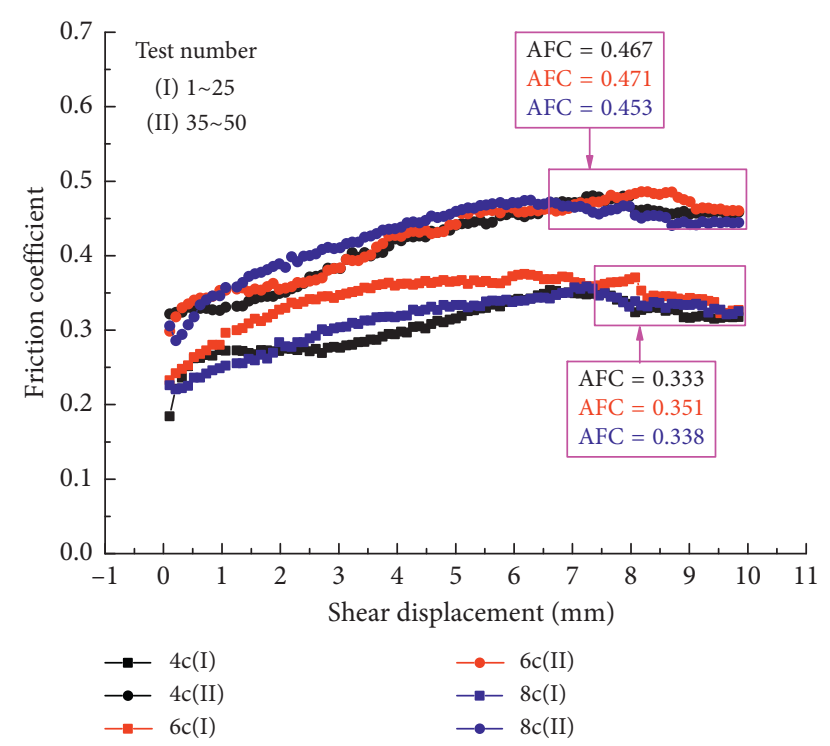

FIGURE 10: Direct shear testing results under pure bentonite slurry.

number of trials increased to 35 . That is, sufficient volume of lubricating slurry on the contact surface corresponded to a small friction coefficient. The severer the loss of the slurry, the faster the increase in the friction coefficient. This shows that the continuous replenishment of lubricating slurry during construction is extremely important for reducing the friction resistance.

As shown in Figure 11, a drop phenomenon was still present in the (I) series curves because of the breakage of debris, and the corresponding AFC varied from 0.450 to 0.470 , which was between $c(I)$ 's $0.333 \sim 0.351$ and $b(\mathrm{I})$ 's $0.573 \sim 0.582$. In the later period, the debris was worn out continuously by the action of compression shear, and the resulting rock flour was mixed with the slurry and stirred to form a highly viscous mixture, which tightly adhered the rock specimen onto the concrete. Hence, the variation range of AFC increased to $0.650-0.654$ in the (II) series curves.

As can be seen from Figure 12, the variation trends of the (I) series curves were similar under the three normal forces since the waste slurry contained a large number of uniformly sized sand grains, and the AFCs varied from 0.425 to 0.451 , which were slightly higher than those for the (I) series curves in condition c. However, as the number of frictions increased, the AFC variation range at the contact surface soared rapidly to about $0.643 \sim 0.650$.

It can be seen from the three (I) curves in Figure 13 that the AFCs concentrated around 0.420 at the initial stage since the waste slurry contained the bentonite slurry, all of which were less than the corresponding three (I) curves in Figure 13, but slightly higher than the three (I) curves in condition c, showing a similar trend as above. Repeated tests caused thickening of the bentonite and waste slurries by continuous mixing and stirring. Meanwhile, the mixed slurry on the contact surface was also continuously extruded, so the AFC for the (II) series curves in Figure 13 soared rapidly to about 0.650 . As shown in Figure 14, the rock specimen was removed from the concrete base after the test.

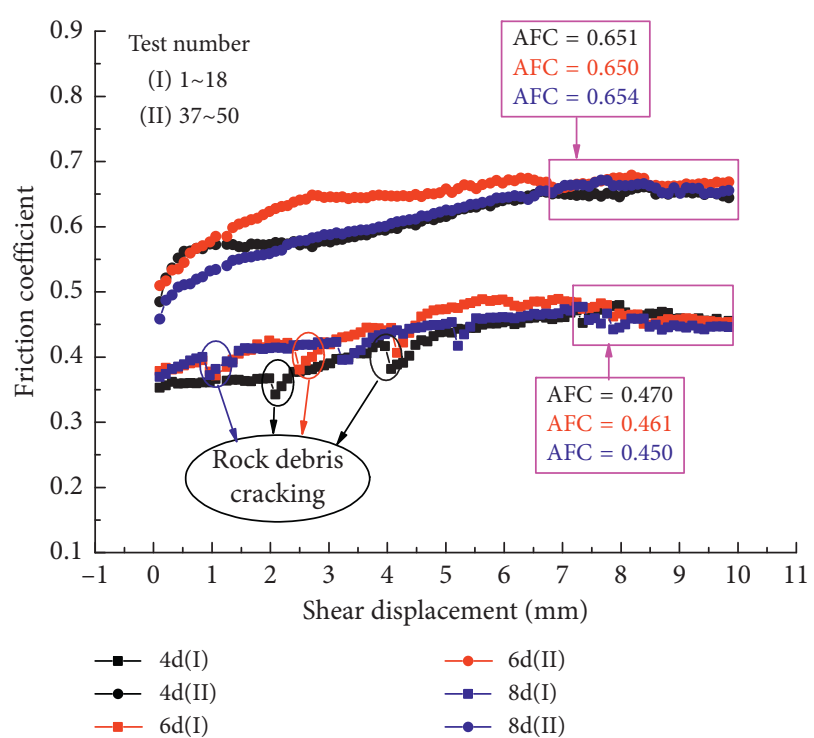

FIGURE 11: Direct shear testing results under a mixture of debris and bentonite slurry.

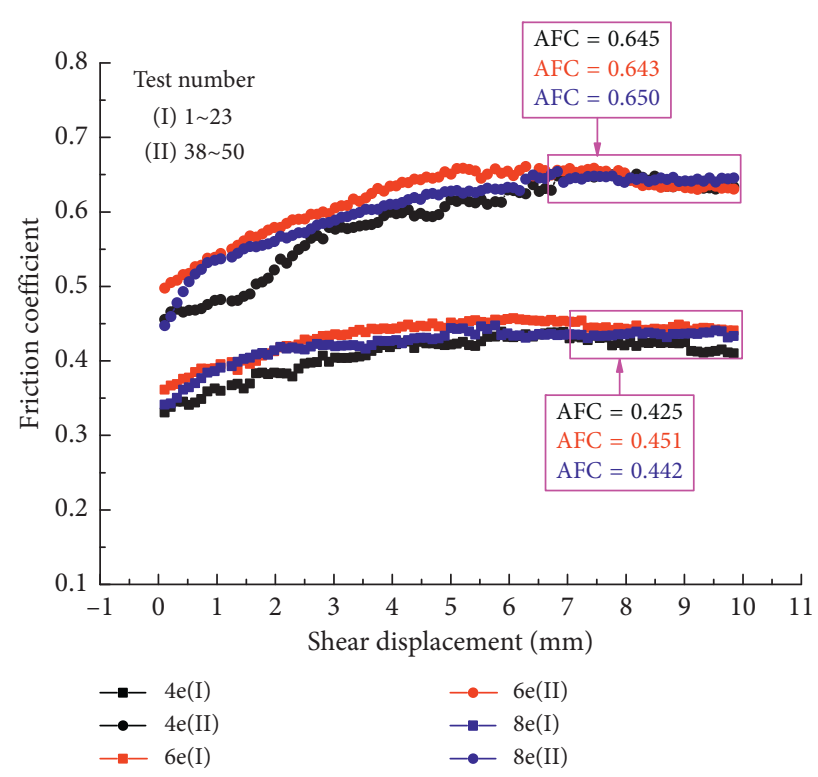

FIGURE 12: Direct shear testing results under the waste slurry condition.

There is an apparent contact mark on the contact surface, indicating that the mixture has higher adhesion to the rock specimen and the concrete base, so the shear resistance is also greater. From this test result, it is clear that the final contact surface AFC in this condition is the highest of the first six types of contact conditions as long as there is no continuous replenishment of the bentonite slurry.

As can be seen from Figure 15, the AFCs of contact surface still concentrated near 0.45 at the initial stage of test, the variation range of AFCs for the three (I) curves was between 0.44 and 0.45 , and the presence of debris again made the AFCs remain slightly higher than those in Figure 13. The drop phenomenon was still present in the (I) 


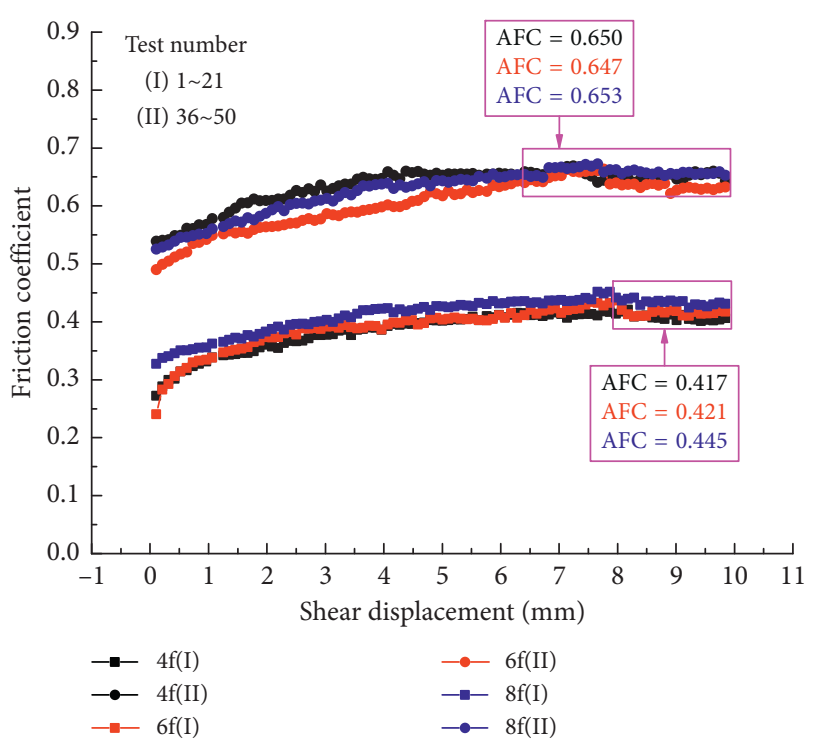

FIGURE 13: Direct shear testing results under a mixture of waste and bentonite slurries.

series curves with the test frequency between 1 and 21 . In the later stage of the test, the cohesive force of the slurry mixture intensified due to the friction at the contact surface and the grinding of debris. Correspondingly, the maximum friction coefficient broke through 0.7 , and AFC, with a value of 0.703 in $8 \mathrm{kN}$ condition, reached the maximum of all tests. Results demonstrate that this contact condition is most unfavorable to the pipe jacking construction among all test conditions.

\section{Monitoring and Prediction of the Jacking Force}

5.1. Comparison of the Jacking Force Monitoring Results for Line 1. After learning the lesson of Line 2, extrapipe deslagging is maintained in the course of jacking aside from continuing to closely monitor the jacking force during the construction of Line 1. Based on the test predictions, the IJS arrangement in Line 1 site is changed as follows. The jacking force for the microshield and the pipe strings (Nos. 1 9) is provided by No. 1 IJS, while the jacking force for the pipe strings (Nos. 11 50) (totalling 40) is provided by No. 2 IJS. According to the in situ deslagging results, the exterior of the pipe strings between the No. 1 and No. 2 IJSs is almost all bentonite slurry during the jacking construction (corresponding to the test condition $\mathrm{c}(\mathrm{I})$ ), as shown in Figure 16(b). Consequently, the jacking force predicted based on the friction test results is compared with the in situ monitored values.

From Figure 16(a), the jacking force predicted by using the empirical formula increases linearly with increasing jacking distance, while the monitored values are overall less than the predictions despite a similar increasing trend with the error range of the two being approximately $20 \%$. Since the total length of the pipe strings is constant after being fully jacked, the predicted jacking force is a certain value, which is approximately $11.3 \mathrm{MN}$, as shown in Figure 16(b). In

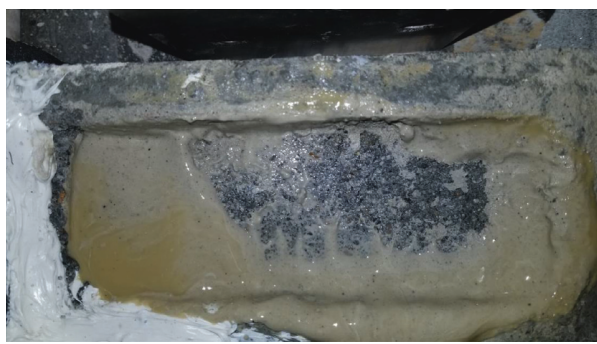

FIGURE 14: Final contact state of contact surface under a mixture of waste and bentonite slurries.

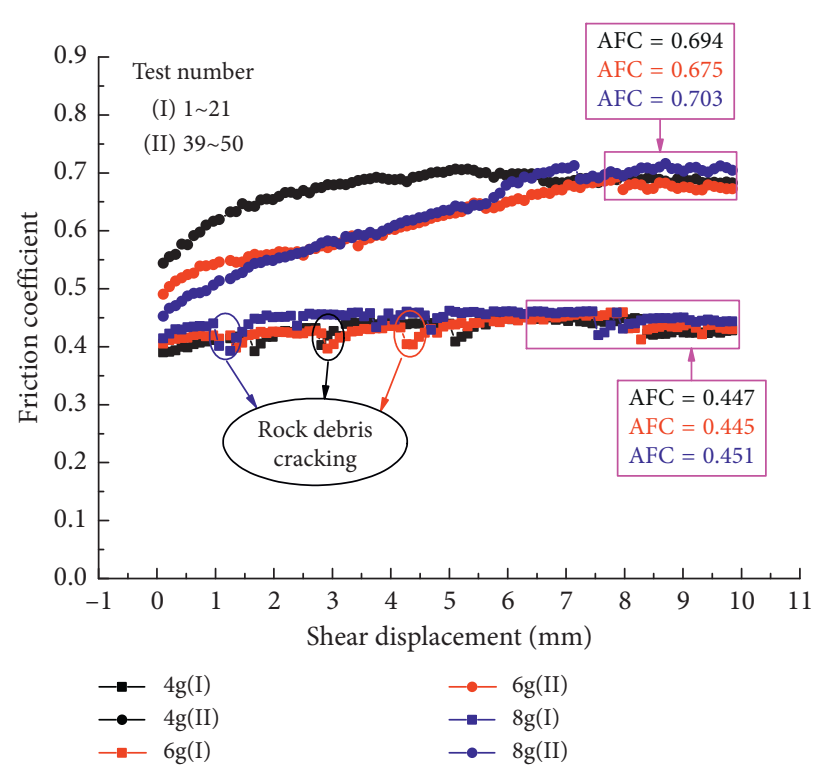

FIgURE 15: Direct shear testing results under a mixture of waste slurry, bentonite slurry, and debris.

contrast, when jacking is initiated on-site, the jacking force increases slightly first, then decreases, and eventually fluctuates within a certain range, which is approximately 10.8 MN on average with an error of approximately $7 \%$. This result implies that the jacking force predicted based on the results of the direct shear test fundamentally and easily reflects the actual site situation. Thus, the method can continue to be used in predicting the variation trends of the jacking force and pipe string wall frictional resistance in other complex settings in conjunction with the contact situation reflected by the pipe string deslagging holes.

5.2. Prediction of the Pipe String Frictional Resistance under Complex Contact Conditions. After obtaining the AFCs between the jacked pipe strings and the surrounding rocks under seven complex contact conditions through indoor direct shear testing, the frictional resistance of pipe strings can be studied by using (1), where $\mathrm{JF}_{\text {frict }}=22000 \mathrm{kN}$ (the maximum safe jacking force of IJSs), $\gamma=25.0 \mathrm{kN} / \mathrm{m}^{3}$, $\varphi_{\mathrm{r}}=31^{\circ}, D=3.17 \mathrm{~m}, r=1.585$, and $L$ is the variable to be solved. The computational results are summarized in Table 4. 


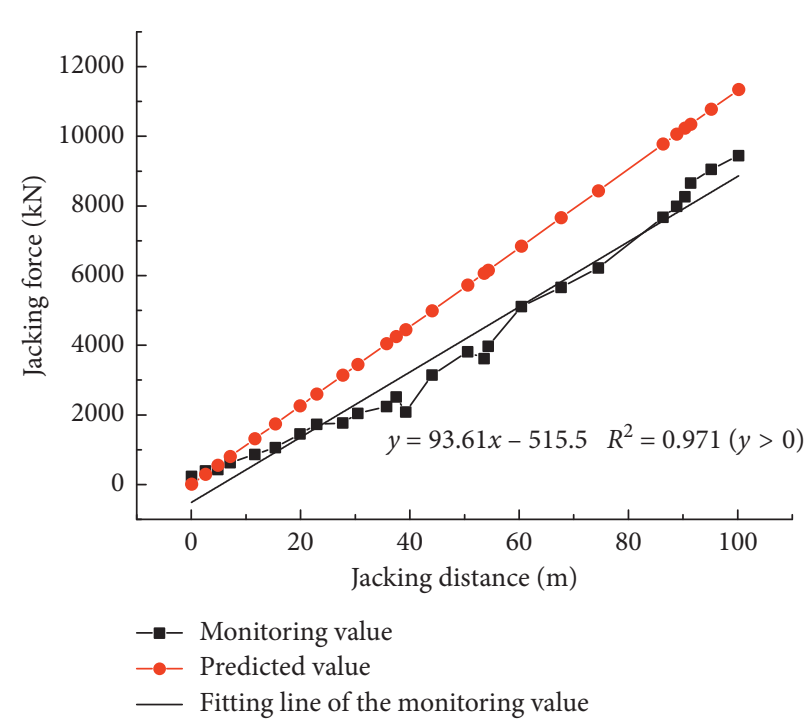

(a)

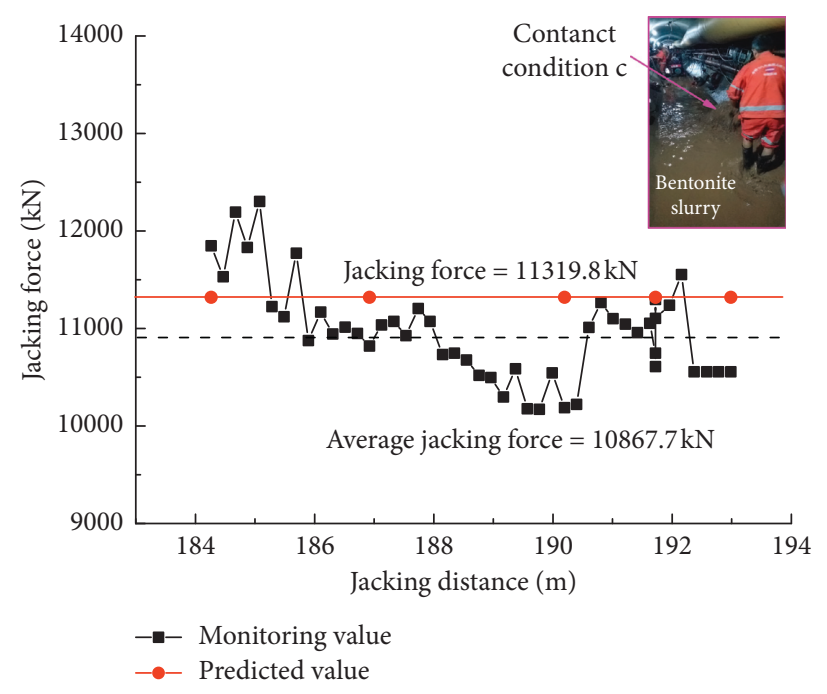

(b)

FIgURE 16: The comparison of jacking forces from monitoring and the empirical equations.

From Figure 17, the maximum numbers of pipe strings that can be driven by adjacent IJSs under different contact conditions are statistically counted. The number of pipe strings between adjacent relays is 59 for Line 2. If Line 1 adopts the same IJS arrangement as Line 2, pipe string sticking may occur under two dry contact conditions, a and b. Regarding the remaining five nondry contact conditions, there is a high probability of pipe string sticking occurrence for series (I) under conditions d, e, f, and g, except for condition $c$, while the calculations of series (II) reveal that the pipe sticking is unavoidable. These results imply that a sufficient bentonite slurry at the pipe string exterior is effective in reducing the frictional resistance produced by complex contact. Meanwhile, the number of pipe strings corresponding to series (II) under condition $g$ is the least among the seven contact conditions, so the occurrence of pipe sticking is more likely under this contact condition onsite. Given Line 1 uses a microshield and pipe strings with the same parameters and specifications as Line 2, to avoid repeating the same mistake, an adjustment to the maximum number of pipe strings driven by IJSs for Line 1 to approximately 35 is advised to ensure the safety of the project.

\section{Conclusion}

(1) It is clear from the variation trends of curves for the seven types of contact friction test results that the friction coefficients at contact surface increase rapidly with the increasing shear displacement initially and then enter a stable variation phase or show a slight decrease (the residual phase). Conditions a and $\mathrm{b}$ are the only two test conditions in which the friction coefficients at contact surface decrease with the increasing number of frictions due to the constant flattening of the contact surface. All the AFCs in the two test conditions drop to 0.55 from the initial value of 0.6 , while the test results for condition b suggest that the wear of debris is helpful in reducing the dry friction coefficient of contact surface.

(2) For all test conditions (conditions c-g) with sufficient bentonite slurry on the contact surface, the initial AFCs are all around 0.4-0.45. As the number of tests increases, the effective slurry volume on the contact surface begins to decrease, and the slurry viscosity increases. In particular, after the formation of debris wear and the mixing of rock flour and waste slurry, the AFC values can be $50 \%-70 \%$ higher than the initial stage values. Thus, the test results show that the effective volume of bentonite slurry on the contact surface plays a decisive role in lowering the friction coefficient of complex contact surfaces. The control of the effective slurry volume on the contact surface is a direction worthy of further research.

(3) Comparison among the results of seven types of concrete-sandstone contact tests reveals that the initial AFCs for the conditions $\mathrm{c}-\mathrm{g}$ are all lower than the conditions $\mathrm{a}$ and $\mathrm{b}$ and that condition $\mathrm{c}$ can be considered as the most ideal pipe-rock contact condition. The magnitudes of AFCs at the contact surface in the later test stage are $\mathrm{g}>\mathrm{f} \approx \mathrm{d}>\mathrm{e}>\mathrm{c}$ in a descending order. The highly viscous bentonite slurry in condition $g$ will form a high-strength hard shell after mixing with coarse and fine debris to adhere tightly onto the pipe-rock contact surface. The increase in the friction resistance of contact surface by the substance not only manifests its high viscosity but also effectively prevents the fresh bentonite slurry from acting on the contact surface again.

(4) The predictive statistics of the number of pipe strings that can be driven by the maximum safe jacking force 
TABle 4: Prediction of the maximum number of pipes driven by adjacent IJSs under different contact conditions.

\begin{tabular}{|c|c|c|c|c|c|c|c|c|c|c|}
\hline Contact condition & Curve series & $\mu_{\mathrm{int}}$ & $\gamma\left(\mathrm{kN} / \mathrm{m}^{3}\right)$ & $r(\mathrm{~m})$ & $\varphi_{\mathrm{r}}\left(^{\circ}\right)$ & $\pi$ & $D(\mathrm{~m})$ & $\mathrm{JF}_{\text {frict }}(\mathrm{kN})$ & $L(\mathrm{~m})$ & Pipe quantity \\
\hline \multirow{2}{*}{ A } & (I) & 0.55 & & & & & & & 123.67 & 49 \\
\hline & (II) & 0.52 & & & & & & & 130.81 & 52 \\
\hline \multirow{2}{*}{ B } & (I) & 0.58 & & & & & & & 117.27 & 46 \\
\hline & (II) & 0.53 & & & & & & & 128.34 & 51 \\
\hline \multirow{2}{*}{ C } & (I) & 0.35 & & & & & & & 194.34 & 77 \\
\hline & (II) & 0.47 & & & & & & & 144.72 & 57 \\
\hline \multirow{2}{*}{ D } & (I) & 0.47 & 25.0 & 1.585 & 31 & 3.14 & 3.17 & 22000 & 144.72 & 57 \\
\hline & (II) & 0.65 & & & & & & & 104.64 & 41 \\
\hline \multirow{2}{*}{$\mathrm{E}$} & (I) & 0.45 & & & & & & & 151.16 & 60 \\
\hline & (II) & 0.65 & & & & & & & 104.64 & 41 \\
\hline \multirow{2}{*}{$\mathrm{F}$} & (I) & 0.44 & & & & & & & 154.59 & 61 \\
\hline & (II) & 0.65 & & & & & & & 104.64 & 41 \\
\hline G & (I) & 0.45 & & & & & & & 151.16 & 60 \\
\hline
\end{tabular}

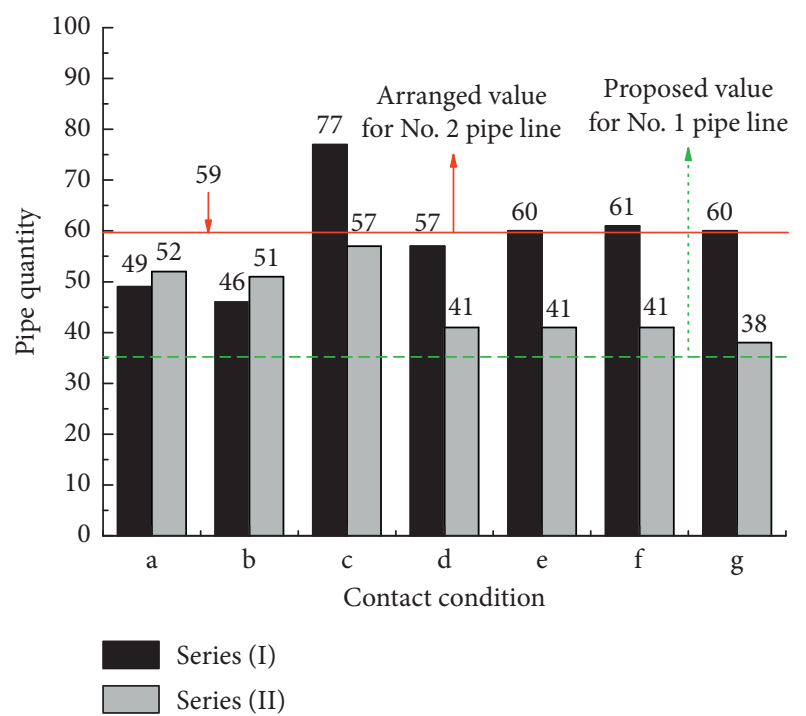

FIGURE 17: Cartogram of the maximum number of pipes driven by adjacent IJSs under different contact conditions.

of the IJSs under various contact conditions using the empirical formula based on the results of seven friction tests indicate a higher probability of pipe sticking for series (I) under conditions c, e, f and $g$ if the number of pipe strings arranged in Line 2 is continued adoption. However, under the remaining contact conditions, pipe sticking is unavoidable. The test results not only explain the importance of bentonite slurry in reducing the pipe string wall frictional resistance again but also more importantly suggest that an increase in the pipe string wall frictional resistance resulting from complex contact inflow into the overexcavation gap is the root cause of pipe sticking and the number of jacked pipe strings matching a single IJS is the second cause of pipe sticking. Hence, combined with the prediction results, we advise that the maximum number of pipe strings corresponding to the IJSs in Line 1 should not exceed 35. In addition, extrapipe deslagging is required during construction to drastically lower the probability of pipe sticking.

(5) The comparison of the predicted versus monitored jacking force reveals that in the course of pipe jacking into a mountain, the jacking force basically increases linearly with jacking distance; after jacking all 40 pipe strings into the mountain, the required average jacking force is close to the monitored value. The predicted values are all slightly higher than the monitored ones, which not only indicates that the predictions fundamentally reflect the actual situation but also suggests that they have certain safety margins. Thus, by predicting the variation trend of the jacking force at any time according to the extrapipe contact condition, the recurrence of pipe sticking can be prevented.

\section{Data Availability}

(1) The field survey data, on-site test data, and laboratory test data which were used to support the findings of this study are included within the article. (2) Previously reported field survey data, on-site test data, and laboratory test data, were used to support this study and are available at WOS: 000449892400047 and WOS:000449698200012. These prior studies (and datasets) are cited at relevant places within the text as references [18] and [19]. (3) The field survey data, onsite test data, and laboratory test data used to support the findings of this study are restricted by the case of actual engineering geological conditions in order to provide reference for similar projects.

\section{Conflicts of Interest}

The authors declare that they have no conflicts of interest.

\section{References}

[1] W. Bergeson, "Review of long drive microtunneling technology for use on large scale projects," Tunnelling and Underground Space Technology, vol. 39, pp. 66-72, 2014. 
[2] B. Ma and M. Najafi, "Development and applications of trenchless technology in China," Tunnelling and Underground Space Technology, vol. 23, no. 4, pp. 476-480, 2008.

[3] T. Senda, Y. Maeda, H. Shimada, T. Sasaoka, and K. Matsui, "Studies on surrounding soil during construction using the deep pipe jacking method in the deep strata," Procedia Earth and Planetary Science, vol. 6, pp. 396-402, 2013a.

[4] T. Senda, H. Shimada, T. Sasaoka, and K. Matsui, "Behavior of surrounding soil during construction and its countermeasures using pipe jacking method in deep strata," Open Journal of Geology, vol. 3, no. 2, pp. 44-48, 2013.

[5] H. Shimada, T. Sasaoka, S. Khazaei, Y. Yoshida, and K. Matsui, "Performance of mortar and chemical grout injection into surrounding soil when slurry pipe-jacking method is used," Geotechnical and Geological Engineering, vol. 24, no. 1, pp. 57-77, 2006.

[6] M. Cheng and Y. Lu, "Developing a risk assessment method for complex pipe jacking construction projects," Automation in Construction, vol. 58, pp. 48-59, 2015.

[7] C. C. Reilly and T. L. L. Orr, "Physical modelling of the effect of lubricants in pipe jacking," Tunnelling and Underground Space Technology, vol. 63, pp. 44-53, 2017.

[8] R. Röhner and A. Hoch, "Calculation of jacking force by new ATV A-161," Tunnelling and Underground Space Technology, vol. 25, no. 6, pp. 731-735, 2010.

[9] K. Shou and J. Jiang, "A study of jacking force for a curved pipejacking," Journal of Rock Mechanics and Geotechnical Engineering, vol. 2, no. 4, pp. 298-304, 2010.

[10] K. Shou, J. Yen, and M. Liu, "On the frictional property of lubricants and its impact on jacking force and soil-pipe interaction of pipe-jacking," Tunnelling and Underground Space Technology, vol. 25, no. 4, pp. 469-477, 2010.

[11] F. Li, K. Fang, and H. Li, "Application of ANSYS 3D FEM in studies of surface deformation caused by pipe jacking," Wuhan University Journal of Natural Sciences, vol. 12, no. 4, pp. 633-637, 2007.

[12] H. Shimada, S. Khazaei, and K. Matsui, "Small diameter tunnel excavation method using slurry pipe-jacking," Geotechnical and Geological Engineering, vol. 22, no. 2, pp. 161186, 2004.

[13] L. Zhen, J.-J. Chen, P. Qiao, and J.-H. Wang, "Analysis and remedial treatment of a steel pipe-jacking accident in complex underground environment," Engineering Structures, vol. 59, pp. 210-219, 2014.

[14] Q.-L. Cui, Y.-S. Xu, S.-L. Shen, Z.-Y. Yin, and S. Horpibulsuk, "Field performance of concrete pipes during jacking in cemented sandy silt," Tunnelling and Underground Space Technology, vol. 49, pp. 336-344, 2015.

[15] V. Andjelkovic, N. Pavlovic, Z. Lazarevic, and V. Nedovic, "Modelling of shear characteristics at the concrete-rock mass interface," International Journal of Rock Mechanics and Mining Sciences, vol. 76, pp. 222-236, 2015.

[16] M. Sanei, L. Faramarzi, A. Fahimifar, S. Goli, A. Mehinrad, and A. Rahmati, "Shear strength of discontinuities in sedimentary rock masses based on direct shear tests," International Journal of Rock Mechanics and Mining Sciences, vol. 75, pp. 119-131, 2015.

[17] X. Wen-Jie, X. Qiang, and H. Rui-Lin, "Study on the shear strength of soil-rock mixture by large scale direct shear test," International Journal of Rock Mechanics and Mining Sciences, vol. 48, no. 8, pp. 1235-1247, 2011.

[18] C. Li, Z. Zhong, C. Bie, and X. Liu, "Field performance of large section concrete pipes cracking during jacking in
Chongqing-a case study," Tunnelling and Underground Space Technology, vol. 82, pp. 568-583, 2018.

[19] C. Li, Z. Zhong, X. Liu, Z. Deng, and G. He, "The investigation of ultra-long-distance concrete pipe stuck in quartz sandstone formation using numerical simulation," Arabian Journal of Geosciences, vol. 11, no. 21, 2018. 


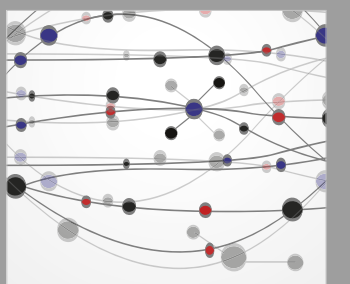

The Scientific World Journal
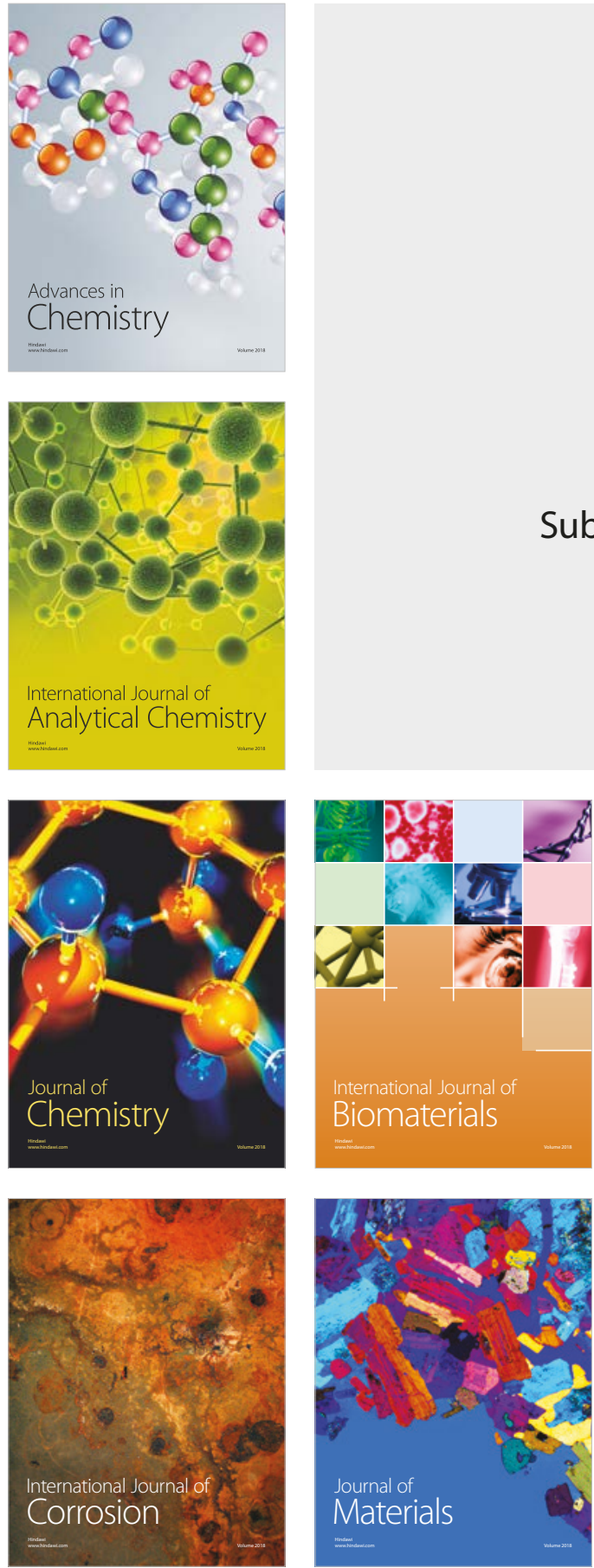

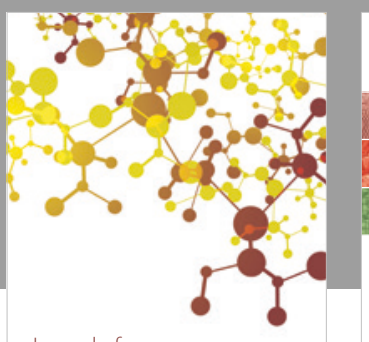

Journal of

Applied Chemistry
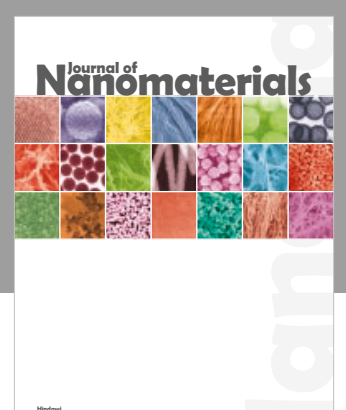

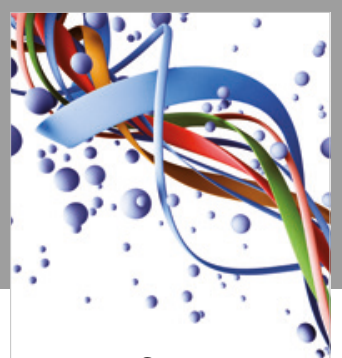

Scientifica

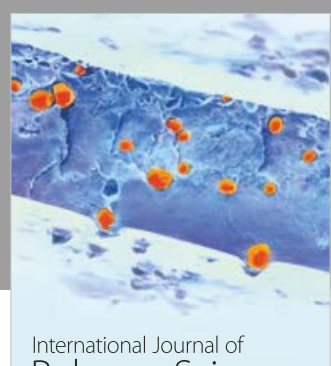

Polymer Science

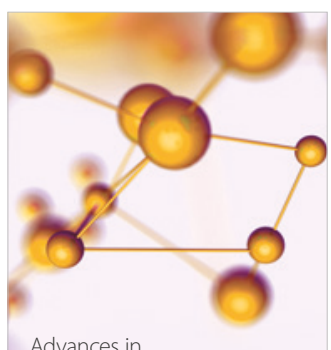

Physical Chemistry
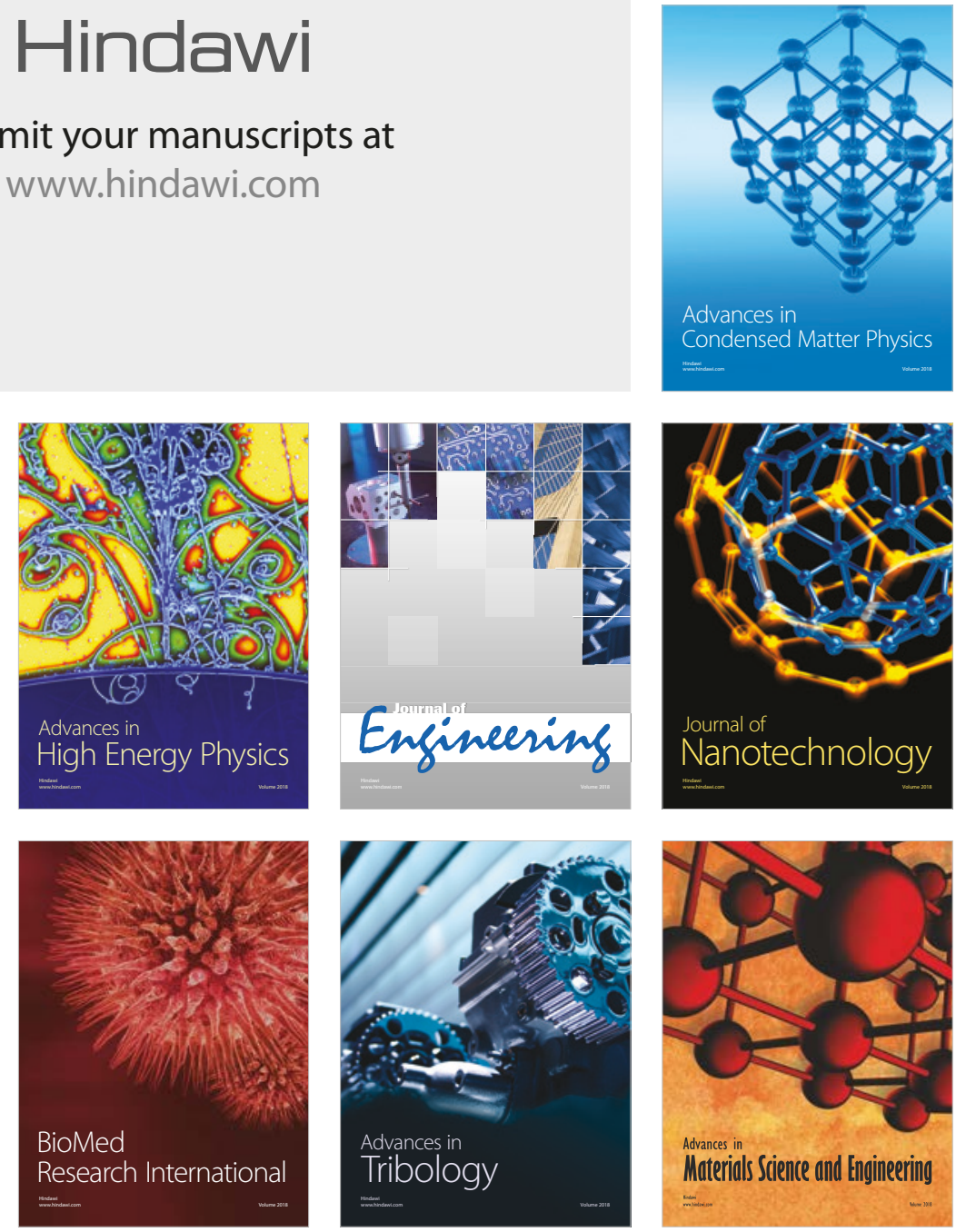